\title{
OFICINAS EDUCACIONAIS: ATIVIDADE DE EXTENSÃO COMO MÉTODO PARA A MELHOR UTILIZAÇÃO DA ENERGIA PARA ESTUDANTES DO ENSINO FUNDAMENTAL
}

\author{
Tiago de Freitas Paulino ${ }^{1}$ \\ Mateus Serra Pinto ${ }^{2}$ \\ Giovani Vitório Costa ${ }^{3}$ \\ Mariana Botarro Bambirra ${ }^{4}$ \\ Eliene de Souza Paulino ${ }^{5}$
}

Resumo: A adequada utilização da energia é conteúdo fundamental para a formação de uma sociedade detentora de uma consciência ecológica e praticante de atos responsáveis que visem o consumo eficiente dos recursos naturais. Nesta temática foi desenvolvido o projeto de extensão Energia para Todos, através de uma equipe multidisciplinar, atuando em uma escola de Contagem (MG). Os trabalhos foram desenvolvidos por meio de oficinas com temas relacionados à energia. Os resultados foram aferidos através de questionários e atividades realizadas pelos alunos. O envolvimento e a qualidade das soluções propostas pelos alunos nos trabalhos demonstram o êxito da metodologia aplicada.

Palavras-chave: Energia; Meio Ambiente; Educação; Atividade de Extensão.

1 CEFET-MG. E-mail: tiagopaulino@deii.cefetmg.br.

${ }^{2}$ CEFET-MG. E-mail: mateuscec@hotmail.com.

${ }^{3}$ CEFET-MG. E-mail: giovanivitorio@gmail.com.

${ }^{4}$ Escola Municipal José Ovídio Guerra. maribotarro@hotmail.com.

${ }^{5}$ Secretaria de Educação de Contagem. eliene.paulino@yahoo.com.br. 


\section{Introdução}

A energia é um dos principais recursos que a sociedade atual utiliza para manter seus inúmeros processos e atividades. Os avanços científicos e tecnológicos, que moldaram o mundo contemporâneo e o modo de vida da comunidade global, desencadearam uma busca por novos meios e fontes de obtenção deste recurso, impactando diretamente o meio ambiente.

Desta forma, o ser humano desenvolveu um novo olhar em relação ao meio ambiente, colocando-o como um recurso a ser utilizado na busca por energia e ignorando a sua própria presença e pertencimento ao mesmo. Sob esse olhar e, com a demanda crescente por energia, iniciou-se uma exploração imediata e predatória. As consequências advindas dessas ações são perceptíveis no mundo atual, ocasionando a urgência de práticas que tenham por objetivo o uso do ambiente de maneira sustentável e renovável.

A degradação ambiental e o uso equivocado de recursos naturais são temas recorrentes no debate político e nas pesquisas acadêmicas. No entanto, percebe-se a necessidade de que toda a sociedade seja envolvida de forma efetiva em ações que fomentem a educação ambiental, como por exemplo, o consumo consciente dos recursos naturais e o uso eficiente da energia (SÁ; OLIVEIRA; NOVAES, 2015a).

A presença da educação ambiental nas instituições escolares, o que se caracteriza como um trabalho promitente, está longe de atender ao requisitado por políticas públicas e leis federais, tal como a Agenda 21 (SÁ; OLIVEIRA; NOVAES, 2015b). Diante dessa realidade, alternativas são criadas, a partir de iniciativas públicas e privadas, com a finalidade de estabelecer, nas escolas, trabalhos multidisciplinares que levem ao corpo discente e à comunidade uma nova perspectiva sobre o uso e importância da preservação do meio ambiente a partir de um consumo eficaz e consciente da energia. Percebe-se, ainda, que a elaboração de materiais didáticos configura um dos principais objetivos dos projetos de temática energética implementados tendo em vista esta perspectiva.

Dada a complexidade e magnitude do tema, observa-se que o foco principal dos materiais supracitados está na redução do consumo de energia elétrica, apoiando-se para isso na reeducação dos atuais consumidores, como é observado nas cartilhas da CPFL Energia (2015) e da Pontifícia Universidade Católica do Rio Grande do Sul (2010), e no ensino ao público infantil, exemplificado pela cartilha da Agência Nacional de Energia Elétrica (2013). Outras iniciativas, porém, buscam estabelecer um panorama completo do assunto, estendendo-se à geração, transmissão e consumo. O conteúdo exposto nas cartilhas da série Energia que Transforma da Fundação Roberto Marinho (2012a, 2012b), e na cartilha de Equipamentos elétricos e eletrônicos (Figueiredo, 2009) elucida essa última situação.

A eficiência da educação ambiental no âmbito escolar é atenuada, porém, quando se verifica a escassez de projetos que busquem estabelecer a 
conexão entre o material didático existente e o público-alvo. Desse modo, a interação entre educador e educando, fundamental para o processo de aprendizagem, é inexistente ou insatisfatória. A utilização dos materiais didáticos, portanto, fica destinada a atividades extraclasses e a curiosidade dos alunos, acarretando em resultados inferiores àqueles obtidos em classe (TEIXEIRA; SOUZA, 2015). Evidencia-se, assim, a importância de atividades que tenham por objetivo a educação ambiental e que tenham por método a interação entre o educador e os alunos, por meio de aulas expositivas e práticas, e atividades que estimulem a busca por novas informações e despertem a curiosidade pelo tema (QUEIROZ et al., 2015).

Sendo assim, o objetivo deste artigo é apresentar o projeto que teve por intuito instruir alunos sobre a importância e a presença da energia no cotidiano, suas formas de geração e impactos ambientais advindos de sua utilização. Ademais, o estudo procurou avaliar os estudantes antes e depois das oficinas por meio da análise dos resultados, que foram aferidos a partir da análise de questionários aplicados aos alunos em momentos distintos e por meio de atividades desenvolvidas por eles no decorrer do projeto. $O$ referido projeto, denominado Energia para Todos, foi desenvolvido como uma atividade de extensão, por meio de uma equipe multidisciplinar formada em uma parceria entre o Centro Federal de Educação Tecnológica de Minas Gerais (CEFETMG), a Secretaria de Educação de Contagem (SEDUC) e a Escola Municipal José Ovídio Guerra (EMJOG). Trata-se de uma iniciativa em caráter piloto implementada na escola, situada em Contagem, Região Metropolitana de Belo Horizonte, Minas Gerais. Espera-se, com essa ação, uma maior compreensão sobre 0 assunto por parte dos estudantes e, consequentemente, uma mudança comportamental dos mesmos, da escola e da comunidade, levando-os a desenvolver práticas e hábitos que visem o consumo da energia de forma eficaz e consciente.

\section{Metodologia}

A metodologia aplicada no processo de ensino foi concebida visando uma melhor experiência aos discentes e eficácia nos resultados. Desta forma, quaisquer práticas e métodos que proporcionem aos alunos uma absorção e fixação satisfatória dos conteúdos ministrados devem ser avaliadas e aplicadas.

Observa-se que a prática alinhada à aula expositiva possui uma eficácia superior aos resultados obtidos nas atividades que não promovam o protagonismo e real envolvimento do aluno (QUEIROZ et al., 2015). Sendo assim, a interação entre os participantes do projeto de extensão e os discentes foi desenvolvida através de atividades práticas, estímulo à busca de novas informações a respeito do conteúdo e desenvolvimento de trabalhos em grupos, que culminaram em apresentações ao final do projeto.

No processo de ensino, a multidisciplinaridade gerada pela integração de diversas áreas do conhecimento na abordagem de um tema é essencial no 
aprendizado e estímulo dos discentes. Tornou-se, portanto, fundamental a participação de membros do corpo docente da EMJOG no projeto desenvolvido, representado pelas professoras de Língua Portuguesa e Ciências.

O projeto foi desenvolvido ao longo de 5 oficinas no período de 11 de setembro de 2015 à 04 de dezembro de 2015. Os alunos envolvidos compreendiam 3 turmas de nível fundamental que cursavam o $9^{\circ}$ ano no período matutino e 2 alunos que cursavam o 6a ano no mesmo período. Esses últimos foram designados por professores e pedagogos da escola, devido ao interesse pelo tema e destaque nas atividades escolares. Em média, cada oficina foi lecionada para 27 alunos.

A fim de considerar o conhecimento dos estudantes sobre a temática de energia, antes e após a realização das oficinas, foram aplicados questionários compostos por questões abertas e de múltipla escolha. A análise dos dados foi realizada utilizando-se o percentual de acertos relativo ao número de questionários respondidos, uma vez que a quantidade de estudantes presentes nos momentos de aplicação dos mesmos diferem entre si.

Concomitantemente às últimas oficinas, ocorria a $21^{\underline{a}}$ Conferência das Partes da Convenção-Quadro das Nações Unidas sobre Mudança do Clima, denominada COP 21. A referida conferência teve por objetivo traçar um novo acordo internacional sobre o clima, no intuito de manter o aquecimento global abaixo dos $2^{\circ} \mathrm{C}$. O evento tornou-se uma fonte adicional de motivação e informação para os alunos.

\section{Oficinas 1, 2 e 3}

Os conceitos e temas abordados nas três oficinas iniciais compreenderam, em geral, conceitos fundamentais sobre energia, formas de geração, transmissão e orientações para redução do consumo de energia elétrica, aquecimento de água a partir do uso da energia térmica solar, energia nos transportes e impactos ambientais. Um conteúdo mais detalhado e dividido por oficinas pode ser observado na Tabela 1. As três oficinas iniciais foram conduzidas pelos membros discentes CEFET-MG e ocorreram, em média, no período de uma hora e trinta minutos.

Os assuntos foram abordados com o auxílio de diferentes recursos didáticos, conforme sua adequação ou complementação no aprendizado dos alunos. A elaboração de todos os materiais utilizados foi precedida por uma extensa revisão bibliográfica, na qual foi realizada a leitura e o estudo de artigos, livros e outros materiais, destacando-se Hinrichs, Kleinbach e Reis (2011), Goldemberg e Lucon (2012), Empresa de Pesquisa Energética (2014), Guerra et al. (2015) e Goldenstein e Azevedo (2006). Procurou-se, também, desenvolver a habilidade de comunicação em público dos membros discentes 
do CEFET-MG, através de apresentações internas de temas relacionados à energia, tecnologia e meio ambiente.

Os principais recursos didáticos utilizados durante as oficinas foram apresentações em formato PowerPoint, a demonstração de fenômenos a partir do uso de protótipos e a exibição de um vídeo. Os protótipos demonstraram a geração de eletricidade por fonte eólica, mecânica ou solar. A exibição do vídeo pertencente à série $\mathrm{Na}$ Trilha da Energia ${ }^{6}$, por sua vez, evidenciou como ocorre a transmissão da energia elétrica no território brasileiro. O conteúdo e os recursos didáticos aplicados nas oficinas foram determinados por meio de reuniões e com o consenso dos membros do projeto. Concomitante às oficinas, os alunos puderam consultar um material didático elaborado, no formato de cartilha, e disponibilizado pelo projeto na escola.

Tabela 1: Conteúdo exposto.

OFICINA CONTEÚDO EXPOSTO NAS OFICINAS

Apresentação inicial do projeto Energia para Todos.

Conceito fundamental de energia.

O crescente uso da energia ao longo do tempo.

Relação entre a tecnologia moderna e a energia.

A energia presente no cotidiano.

1 Formas de obtenção de energia.

Fontes renováveis e fontes não renováveis.

Transmissão da energia elétrica.

Geração doméstica de energia: aquecimento de água via energia térmica solar.

O uso da energia no Brasil a partir do consumo por setores.

As principais formas de energia utilizadas no Brasil.

Impactos ambientais oriundos da geração e consumo.

Transmissão da energia elétrica.

Matriz elétrica brasileira.

2 Descrição do funcionamento das usinas elétricas listadas e seus respectivos

benefícios e impactos ambientais, sociais e econômicos: hidrelétrica, termelétrica,

nuclear, eólica, termelétrica solar e geração a partir de painéis fotovoltaicos.

ONS - Operador Nacional do Sistema Elétrico.

O uso da energia em casa.

Definição de consumo de energia elétrica.

Definição de eficiência energética.

Demonstração do selo Procel.

Dicas para redução do consumo de energia elétrica.

A energia nos transportes.

3 Combustíveis fosseis: gasolina, óleo diesel e gás natural.

Combustíveis renováveis: etanol, biodiesel e biogás.

O uso de combustíveis no Brasil.

Combustíveis alternativos: eletricidade e hidrogênio.

O uso do transporte público e alternativas para o transporte.

Transporte de carga e os seus respectivos benefícios e malefícios: marítimo, ferroviário e rodoviários.

Programa CONPET.

Fonte: Autoria própria.

${ }^{6}$ http://www.natrilhadaenergia.com.br/ 
Os protótipos (Figura 1), foram desenvolvidos com base em tutoriais encontrados em sites e canais de vídeos na internet, sendo o Manual do Mundo Comunicação $\operatorname{LTDA}^{7}$ a principal fonte consultada. $O$ objetivo primordial quanto ao uso desse recurso foi estabelecer um melhor canal de comunicação entre os alunos e os membros discentes do CEFET-MG, despertado pela curiosidade dos discentes em compreender o funcionamento dos protótipos. Destaca-se, também, a melhor compreensão dos alunos a respeito dos fenômenos demonstrados e a maior facilidade na transmissão do conhecimento com o auxílio dos protótipos.
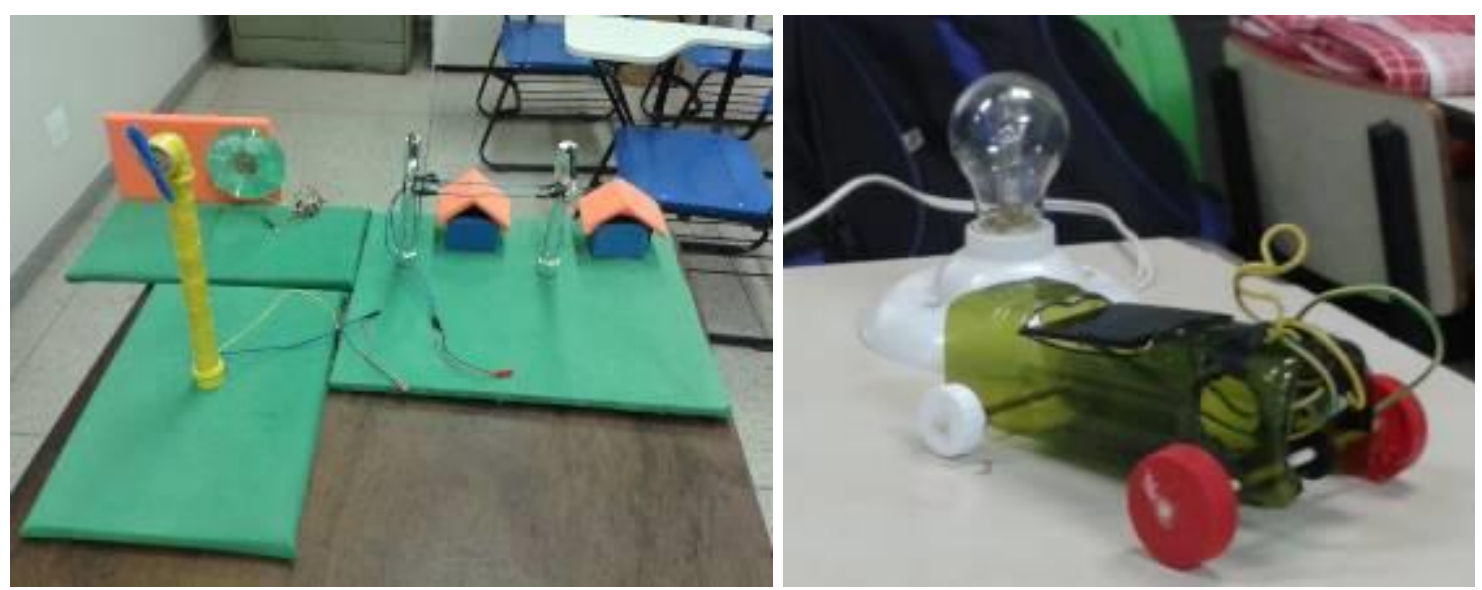

Figura 1: Protótipos utilizados nas oficinas.

Fonte: Autoria própria (2015).

A cartilha distribuída foi concebida com a finalidade de oferecer aos alunos uma fonte de pesquisa de fácil acesso e com linguagem simples e direta, facilitando o entendimento dos mesmos. Desse modo, os estudantes que levantassem dúvidas durante a elaboração do trabalho proposto poderiam buscar no material desenvolvido uma referência básica para a sua pesquisa, expandindo-a conforme a sua necessidade. As informações presentes na cartilha foram obtidas a partir de fontes diversificadas. Cita-se, como principais referências, ações governamentais e projetos de iniciativa privada, dentre elas o projeto Academia de Ciência do Instituto Braudel ${ }^{8}$ (2012), o programa CONPET $^{9}$, oriundo de uma iniciativa do Ministério de Minas e Energia em parceria com a Petrobrás, e o portal online do departamento de física da Universidade Federal do Paraná ${ }^{10}$.

O estudo de temas específicos da cartilha foi realizado com a orientação da professora de Ciências. Foi promovida a leitura e discussão a respeito dos temas, além de atividades curriculares com a temática baseada no material.

7 http://www.manualdomundo.com.br/

8 http://www.academiadeciencia.org.br/site/

9 http://www.conpet.gov.br/

${ }^{10}$ http://fisica.ufpr.br 
A terceira oficina foi utilizada para a proposição de um trabalho aos discentes, além da apresentação do conteúdo descrito na Tabela 1. O trabalho teve por objetivo promover o protagonismo e o envolvimento dos alunos, estimulando discussões a respeito do tema e aferindo a eficácia na transmissão do conhecimento. Para tanto, os alunos foram divididos em grupos de 4 ou 5 membros. A divisão dos grupos foi realizada pelas professoras da escola, devido ao conhecimento prévio e maior contato com esses estudantes. Os temas designados para os grupos estão listados na Tabela 2.

Tabela 1: Temas dos trabalhos.

\begin{tabular}{ll}
\hline \multicolumn{1}{c}{ TEMAS } & \multicolumn{1}{c}{ OBJETIVO } \\
\hline $\begin{array}{l}\text { Levantamento de alternativas para } \\
\text { aquecimento de água para banho } \\
\text { na escola. }\end{array}$ & $\begin{array}{l}\text { Levantar alternativas que possibilitem adequado } \\
\text { aquecimento de água para banho na escola. Esta } \\
\text { demanda foi levantada pela EMJOG ao início do projeto. }\end{array}$ \\
\hline $\begin{array}{l}\text { Ações para melhor utilização da } \\
\text { energia em uma residência. }\end{array}$ & $\begin{array}{l}\text { Propor adequações que possibilitem a uma residência } \\
\text { maior eficiência no uso da energia e uma utilização que } \\
\text { gere menos impactos ambientais. }\end{array}$ \\
\hline Alternativas para transporte. & $\begin{array}{l}\text { Levantar alternativas que possibilitem o transporte com } \\
\text { menor impacto ambiental para a cidade de Contagem. }\end{array}$ \\
\hline $\begin{array}{l}\text { Ações para melhor utilização da } \\
\text { energia na escola. }\end{array}$ & $\begin{array}{l}\text { Propor adequações que possibilitem, na escola, maior } \\
\text { eficiência no uso da energia e uma utilização que gere } \\
\text { menos impactos ambientais. }\end{array}$ \\
\hline
\end{tabular}

Fonte: Autoria própria.

Buscando-se auxiliar os alunos na confecção dos trabalhos, foi criado um roteiro composto por uma sequência lógica de questões. Dessa forma, os alunos tiveram um direcionamento para a solução dos problemas propostos, constituído pela identificação do problema, metodologia para a sua solução e levantamento dos resultados positivos e negativos advindos do passo anterior. Ressalta-se que os roteiros eram específicos para cada tema.

Posterior a cada oficina, os alunos foram orientados pela professora de Língua Portuguesa a redigirem um relatório, com a finalidade de promover uma reflexão crítica a respeito dos conteúdos ministrados. As dúvidas, comentários e sugestões dos alunos durante e após a elaboração dos relatórios eram relatadas à professora, que as repassava à equipe do projeto.

\section{Oficina 4}

A quarta oficina surgiu com base em uma necessidade levantada pelo corpo de professores e pedagogos da EMJOG e da SEDUC. Estimou-se, assim, a importância de uma quarta oficina, antecessora às apresentações, que tivesse por intuito sanar quaisquer dúvidas dos alunos a respeito do trabalho, orientando-os em possíveis melhorias e acréscimos e incentivando-os pelos pontos positivos construídos. Sendo assim, a quarta oficina ocorreu no modelo de uma reunião individual entre cada um dos grupos e os membros do projeto de extensão. 
Os grupos, ao exporem seus trabalhos, foram parabenizados pelo empenho. Todos os pontos positivos foram destacados, como a criatividade e eficácia das soluções apresentadas para o respectivo tema, qualidade do material elaborado por eles para a apresentação e o real envolvimento de todos os participantes no trabalho. Levantou-se, posteriormente, pontos passíveis de melhoria. Em geral, sugeriu-se aos grupos uma ampliação da pesquisa realizada, com a busca de outras soluções. Além disso, foi destacada a importância da clareza na apresentação do trabalho e da diversificação dos recursos utilizados.

\section{Oficina 5}

A quinta oficina foi designada para a apresentação dos trabalhos desenvolvidos pelos alunos aos membros do projeto de extensão e representantes da SEDUC, da Secretaria de Política Estudantil (SPE) do CEFET-MG e professores e pedagogos da EMJOG.

\section{Resultados e discussão}

Os resultados do projeto foram aferidos por meio da comparação entre as informações obtidas pelo questionário aplicado antes e após as oficinas e pela análise das apresentações dos trabalhos realizados pelos alunos.

A análise das respostas fornecidas pelos estudantes demonstra um avanço na compreensão dos temas expostos. Observa-se que os alunos desenvolveram uma definição mais ampla sobre energia. Inicialmente, quando indagados a respeito do conceito de energia, a maioria dos alunos restringia-se a apresentar o sinônimo de eletricidade. Contudo, findado o projeto, os alunos afirmaram que energia é a capacidade de provocar alterações em um meio, destacando suas diversas formas e incluindo-a em todos os ambientes.

Quanto ao conceito de eficiência energética, a situação foi semelhante. O significado do termo, sua aplicação e importância eram desconhecidos pela maioria dos alunos. Entretanto, o índice de alunos que afirmaram compreender o termo aumentou, conforme explicitado na Figura 2. Aliado a isso, os alunos citaram o selo Procel como método de reconhecimento e aferição da eficiência de um aparelho. 


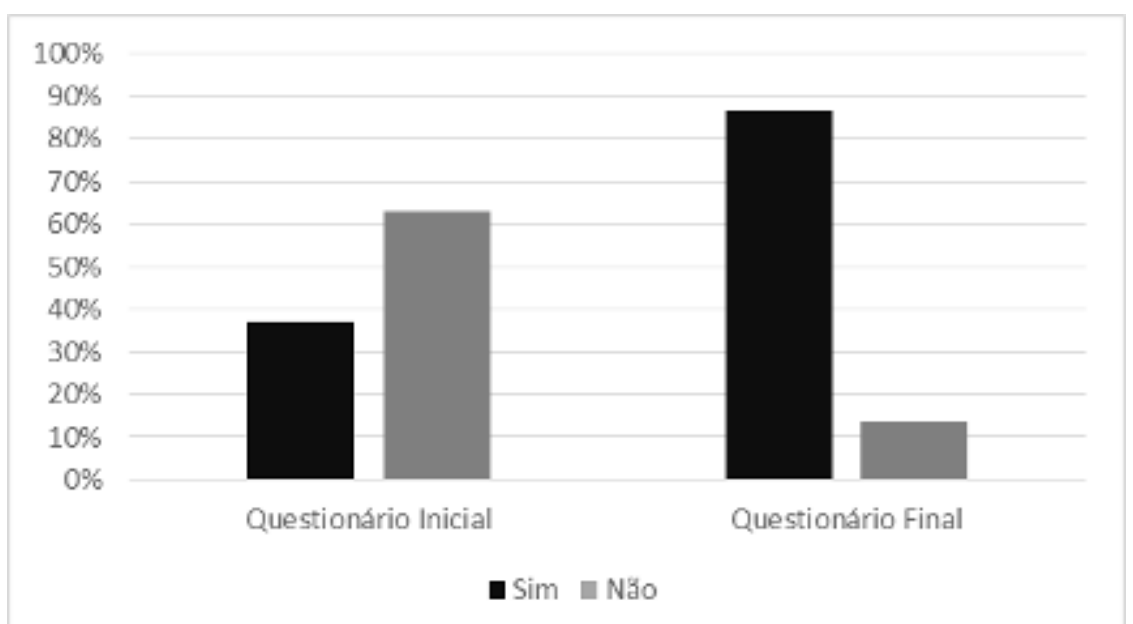

Figura 2: Índice de alunos que afirmaram entender o que é eficiência energética antes e após o projeto. Fonte: Autoria própria (2015).

Percebe-se, também, que a maioria dos alunos não compreendia os conceitos de energia renovável e energia não renovável. Assim, quando foi solicitado aos mesmos que classificassem fontes de energia diversas segundo tais conceitos, o índice de acerto manteve-se discreto. A comparação entre os questionários inicial e final é demonstrada na Figura 3.

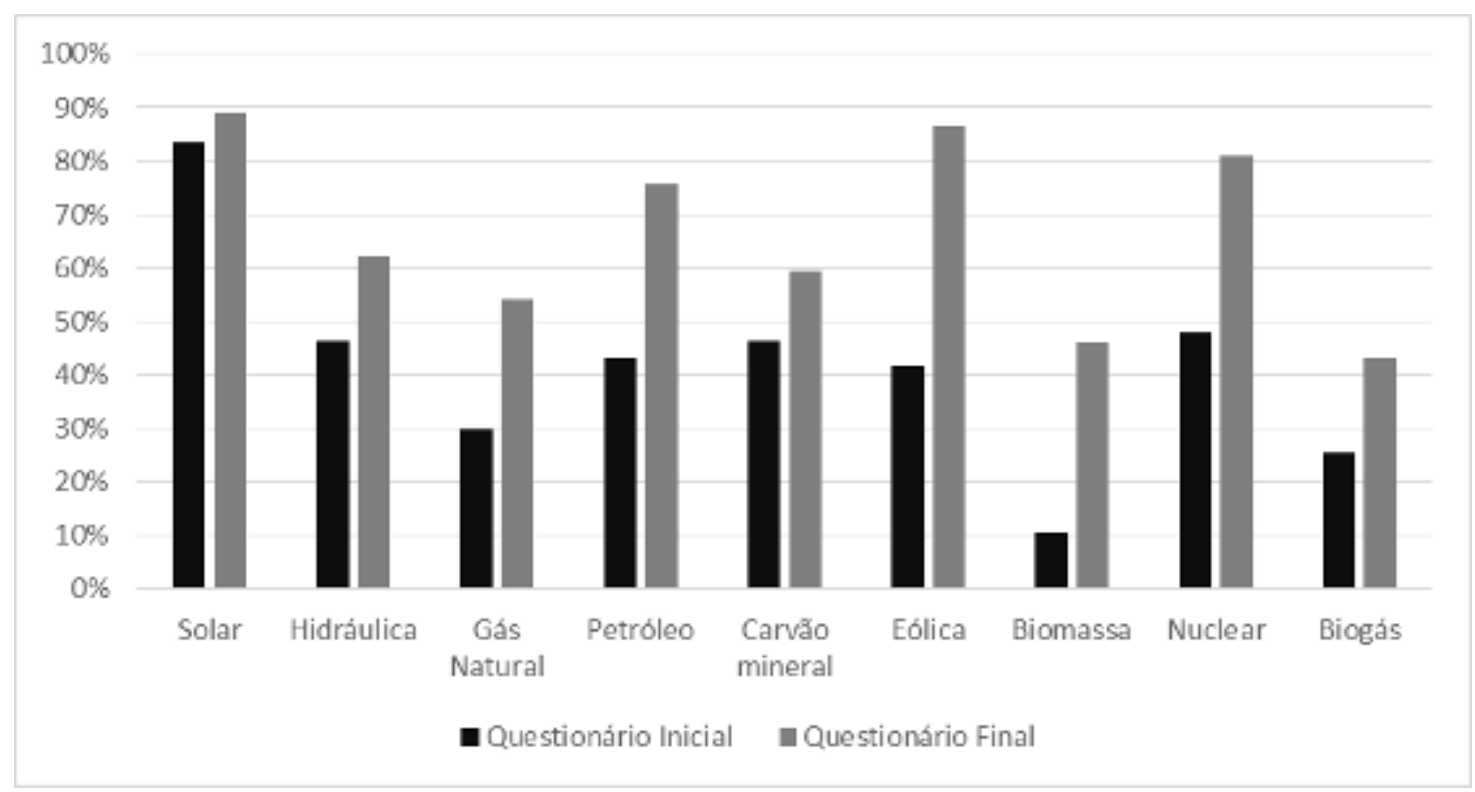

Figura 3: Índice de acertos dos alunos ao classificarem fontes de energias diversas como renováveis ou não renováveis nos questionários inicial e final. Fonte: Autoria própria (2015).

Os trabalhos confeccionados pelos estudantes foram expostos a partir de apresentação oral e uso de recursos didáticos diversos, como maquetes, cartazes e apresentações no PowerPoint (Figura 4). Nota-se que os alunos demonstraram comprometimento e empenho no decorrer das atividades, 
culminando em um conteúdo abrangente e coerente com o tema proposto. Os resultados oriundos dos trabalhos, devido a semelhança das soluções apresentadas entre os grupos, foram agrupados conforme a sua temática.

A apresentação do grupo, cujo tema era Levantamento de alternativas para o aquecimento de água para banho na escola, apontou como principal solução a implementação de chuveiros com aquecedor solar de baixo custo em detrimento dos chuveiros elétricos que estão em uso na escola, detalhando o princípio de funcionamento, a confecção e a instalação do equipamento. Visando sustentar a melhoria apresentada, argumentaram que essa alternativa reduziria os custos relativos a eletricidade e os impactos ambientais advindos de seu uso. O reuso da água utilizada nos banhos foi proposto por um dos grupos, buscando a redução do consumo de água e energia. Faz-se significativo explicitar que essa solução apresentada não configura parte do conteúdo lecionado aos alunos, indicando, portanto, autonomia e interesse dos discentes.

O uso do aquecedor solar de baixo custo foi igualmente citado no tema Ações para melhor utilização da energia em uma residência, com seu uso voltado para chuveiros e torneiras. Além disso, os trabalhos referentes a esse tema apontaram o uso de equipamentos eficientes e o consumo consciente como formas de redução e otimização no uso da energia. Ações referentes a estrutura física da residência foram ressaltadas e consistem no uso de telhados e paredes em cor clara, janelas amplas e instalação de placas fotovoltaicas.
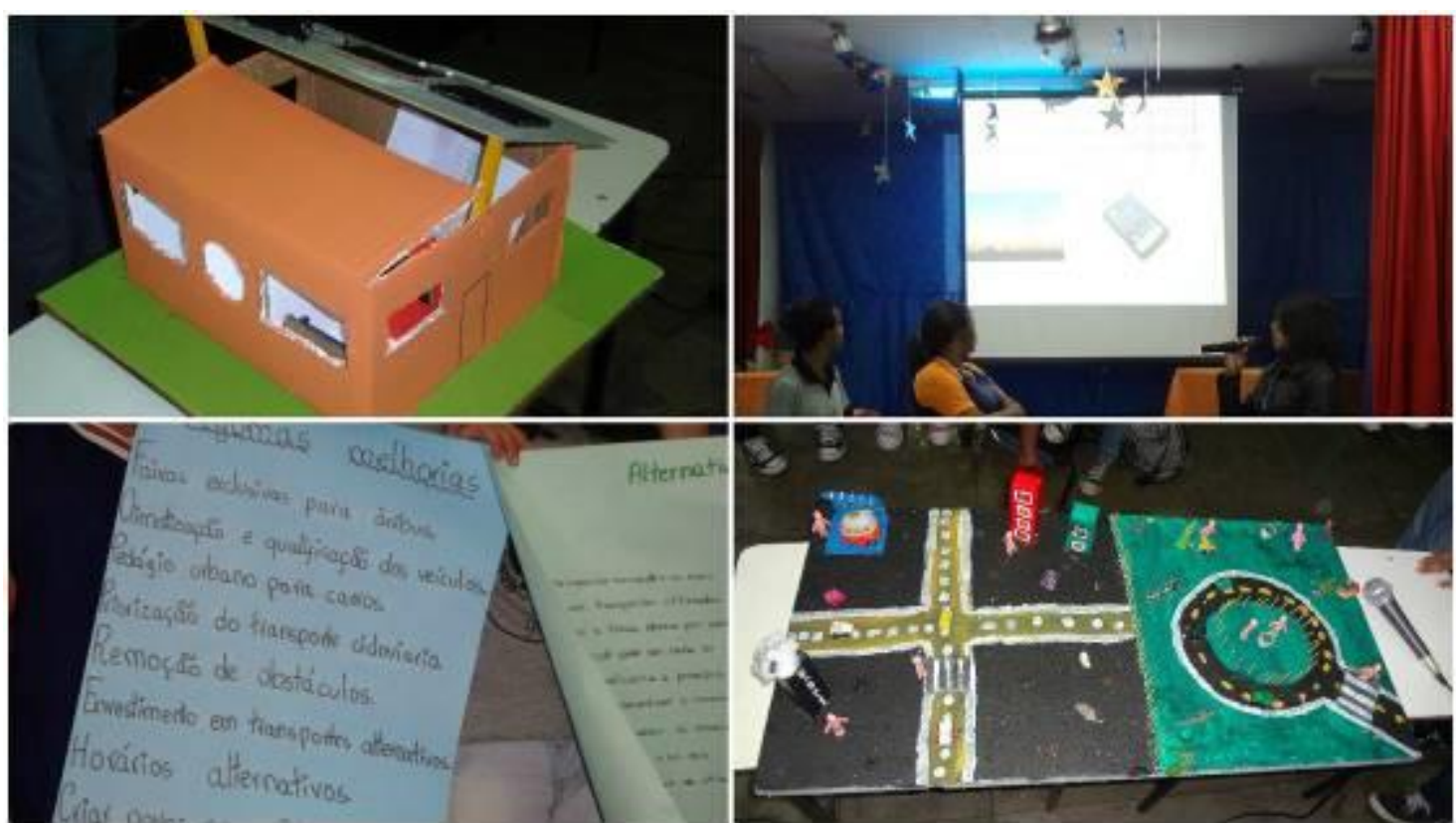

Figura 4: Recursos didáticos elaborados e apresentados pelos alunos da EMJOG. Fonte: Autoria própria (2015).

O tema Ações para melhor utilização da energia na escola possuiu 
destaque dos trabalhos dessa temática consistiu no mapeamento realizado pelos alunos dos pontos passíveis de melhorias na EMJOG (Figura 5). Foram sugeridos a utilização de sensores de presença para locais de fluxo inconstante de pessoas e o uso de iluminação natural das salas a partir da modificação das janelas atuais.

No que se refere ao tema Alternativas para transporte, os estudantes iniciaram discussões a respeito dos impactos ambientais provenientes do uso da energia, citando a COP 21 e as propostas brasileiras, e expuseram as principais vantagens e desvantagens presentes no uso de carros com painéis solares e carros elétricos, destacando o custo de implementação dessas tecnologias e suas eficiências. O uso de transportes alternativos e de práticas sociais, como o transporte público, bicicletas e carona, foram incentivados. Foi destacada a necessidade de um bicicletário na escola. Uma maquete foi apresentada, vide Figura 4, ilustrando de modo fantasioso a situação atual do transporte em Contagem e comparando-a com uma perspectiva de futuro onde as soluções por ele apresentadas fossem aplicadas.

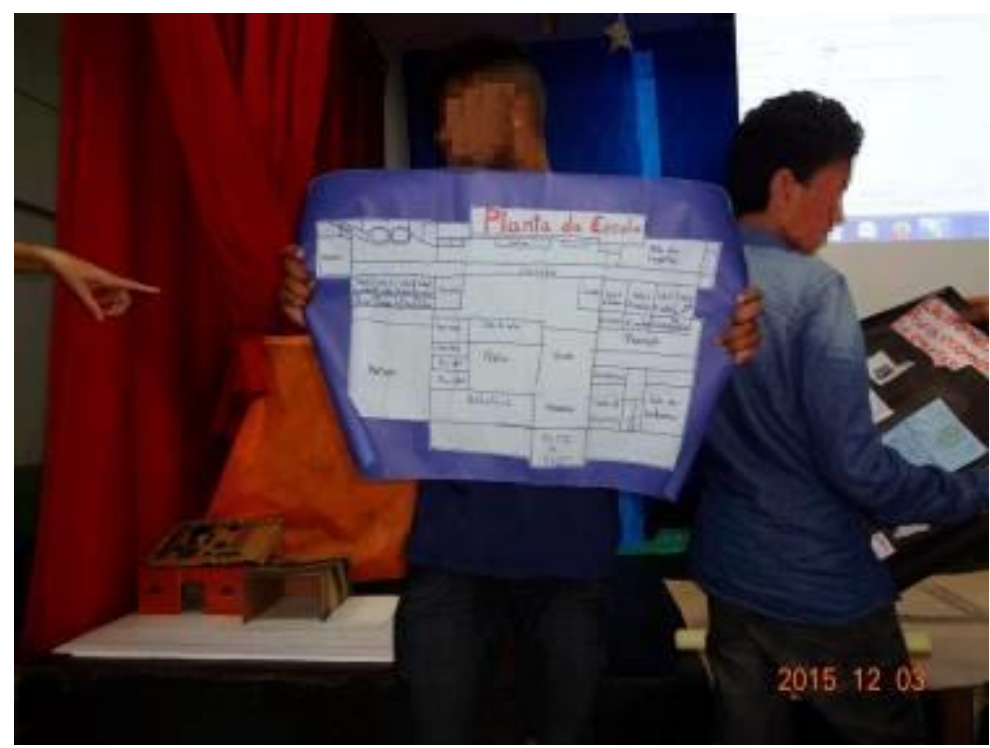

Figura 5: Mapeamento da escola feito pelos alunos.

Fonte: Autoria própria (2015).

\section{Conclusões}

A construção de uma sociedade sustentável é imprescindível no atual cenário ambiental. A constante degradação do meio ambiente e os impactos advindos da exploração e consumo desenfreados dos recursos naturais torna insustentável a perpetuação de práticas ambientalmente irresponsáveis.

Desse modo, o conhecimento dos processos de geração e transmissão da energia e os impactos ambientais advindos de seu consumo evidenciaram aos alunos a relevância das práticas e ações que visem a diminuição do consumo de energia. A execução de tais ações, devido ao estímulo ao protagonismo dos alunos na execução das atividades e o constante incentivo 
ao debate e pesquisa do tema, foi posta em prática, expandindo-se ao cotidiano dos discentes, à comunidade escolar e à residência dos mesmos.

A realização de um trabalho mais prolongado com o corpo de alunos mostrou-se fundamental para a plena compreensão dos conteúdos, dadas a complexidade e magnitude do tema. A participação de professores e pedagogos da EMJOG e da SEDUC foi de extrema importância para a existência e êxito do projeto, devido ao conhecimento prévio das diversas personalidades dos estudantes. Desse modo, a abordagem aplicada no processo de ensino foi moldada conforme orientações dadas pelos professores e pedagogos, objetivando o aproveitamento máximo dos alunos. Reforça-se, portanto, a necessidade e eficácia da interação entre diferentes instituições educacionais.

\section{Agradecimentos}

Os autores agradecem à SPE pelo aporte financeiro, à SEDUC e a equipe da EMJOG pela parceria e por acreditarem nesta iniciativa.

\section{Referências}

Agência Nacional de Energia Elétrica. Use a Energia com Inteligência. Brasília: $\quad$ ANEEL, 2013. Disponível em http://www2.aneel.gov.br/biblioteca/downloads/livros/Cartilha use energia.pdf. Acesso em: 05 mai. 2015.

CPFL Energia. 2015. Programa de Eficiência Energética. Sua Energia Transforma o Mundo. Campinas: CPFL Energia. Disponível em http://www.cpfl.com.br/energias-sustentaveis/eficienciaenergetica/Documents/cartilha-ee-ago15.pdf. Acesso em: 16 set. 2015.

DEPARTAMENTO DE FíSICA - Universidade Federal do Paraná. Disponível em: <http://fisica.ufpr.br/>. Acesso em: 07 ago. 2015.

Empresa de Pesquisa Energética - EPE. Balanço Energético Nacional (BEN) 2014: Ano base 2013. Rio de Janeiro: EPE, 2014.

FIGUEIREDO, C.R. Equipamentos elétricos e eletrônicos. Brasília: Universidade de Brasília, 2009.

FUNDAÇÃO ROBERTO MARINHO. Revelando a energia: volume 2. - 1.ed. Rio de Janeiro: Fundação Roberto Marinho, 2012a. Recuperado a partir de http://www.procelinfo.com.br/main.asp?View=\{B3D1FEAA-D2F3-4A5F-A6AA84627E9BB4EC\}. Acesso em: 15 mar. 2015.

FUNDAÇÃO ROBERTO MARINHO. Textos: volume 3. Rio de Janeiro: Fundação Roberto Marinho, 2012b. Recuperado a partir de http://www.procel.gov.br/main.asp?View=\%7BB3D1FEAA-D2F3-4A5F-A6AA84627E9BB4EC\%7D. Acesso em: 15 mar. 2015. 
GOLDEMBERG, J.; LUCON, O. Energia, Meio Ambiente e Desenvolvimento. 3ª Ed. São Paulo: Ed. da Universidade de São Paulo, 2012. GOLDENSTEIN, M.; AZEVEDO, R.L.S. Combustíveis alternativos e inovações no setor automotivo: será o fim da "era do petróleo"?. BNDES Setorial, Rio de Janeiro, v. 23, p. 235-266, 2006.

GUERRA, J.B.S.O.A.; DUTRA, L.; SCHWINDEN, N.B.C.; ANDRADE, S.F. Future scenarios and trends in energy generation in Brazil: supply and demand and mitigation forecasts. Journal of Cleaner Production, v.103, p. 197-210, 2015.

HINRICHS, R.A.; KLEINBACH, M.; REIS L.B. Energia e Meio ambiente. São Paulo: Cengage, 2011.

INSTITUTO BRAUDEL. Academia de Ciência. Disponível em: http://www.academiadeciencia.org.br/site/. Acesso em: 17 jun. 2015.

NA TRILHA DA ENERGIA. Disponível em: http://www.natrilhadaenergia.com.br/. Acesso em 19 ago. 2015.

MANUAL DO MUNDO. Disponível em: http://www.manualdomundo.com.br/. Acesso em: 14 jun. 2015.

MINISTÉRIO DE MINAS E ENERGIA. CONPET. Disponível em: http://www.conpet.gov.br/. Acesso em: 03 abr. 2015.

PONTIFÍCIA UNIVERSIDADE CATÓLICA DO RIO GRANDE DO SUL. Faculdade de Engenharia. Grupo de Eficiência Energética. USE - Uso Sustentável da Energia: guia de orientações / PUCRS, FENG, GEE, PU. Porto Alegre: PUCRS, $2010 . \quad$ Disponível em http://www.pucrs.br/biblioteca/manualuse.pdf. Acesso em: 20 mai. 2015.

QUEIROZ, M.T.A. et al. Oficinas educativas: qualidade da água e proteção ambiental. Revista Brasileira de Educação Ambiental, v. 10, n. 2, p. 176-186, 2015.

SÁ, M.A.; OLIVEIRA, M.A.; NOVAES, A.S.R. A importância da educação ambiental para o ensino médio. Revista Brasileira de Educação Ambiental, v. 10 , n. 3, p. $60-68,2015 a$.

SÁ, M.A.; OLIVEIRA, M.A.; NOVAES, A.S.R. Educação ambiental nas escolas estaduais de floresta (PE). Revista Brasileira de Educação Ambiental, v. 10, n. 1, p. 118-126, 2015b.

TEIXEIRA, R.S.; SOUZA, R.O.L. Análise de materiais educativos utilizados como ferramenta para a educação ambiental de estudantes de escolas públicas do Rio de Janeiro. Revista Eletrônica em Gestão, Educação e Tecnologia Ambiental, v. 19, n. 2, p. 1032-1037, 2015. 